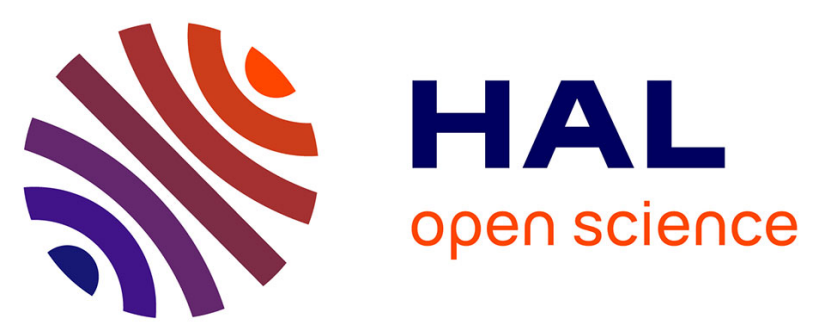

\title{
THEORETICAL PROCEDURE TO OBTAIN THE MECHANICAL BEHAVIOUR OF POROUS MATERIALS BY THE BIOT'S THEORY AND THE CONTINUITY EQUATIONS
}

\author{
T. Gomez, E. Riera, J. Gallego
}

\section{To cite this version:}

T. Gomez, E. Riera, J. Gallego. THEORETICAL PROCEDURE TO OBTAIN THE MECHANICAL BEHAVIOUR OF POROUS MATERIALS BY THE BIOT'S THEORY AND THE CONTINUITY EQUATIONS. Journal de Physique IV Proceedings, 1992, 02 (C1), pp.C1-767-C1-770. 10.1051/jp4:19921167 . jpa-00251127

HAL Id: jpa-00251127 https://hal.science/jpa-00251127

Submitted on 1 Jan 1992

HAL is a multi-disciplinary open access archive for the deposit and dissemination of scientific research documents, whether they are published or not. The documents may come from teaching and research institutions in France or abroad, or from public or private research centers.
L'archive ouverte pluridisciplinaire HAL, est destinée au dépôt et à la diffusion de documents scientifiques de niveau recherche, publiés ou non, émanant des établissements d'enseignement et de recherche français ou étrangers, des laboratoires publics ou privés. 


\title{
THEORETICAL PROCEDURE TO OBTAIN THE MECHANICAL BEHAVIOUR OF POROUS MATERIALS BY THE BIOT'S THEORY AND THE CONTINUITY EQUATIONS
}

\author{
T. GOMEZ, E. RIERA and J.A. GALLEGO \\ Instituto de Acùstica, CSIC, Serrano 144, SP-28006 Madrid, Spain
}

\begin{abstract}
Résumé -Dans 1'application de la théorie de Biot une des difficultés est la charactérisation méchanique du materiel poreux (les coeffients de Biot $P, Q$ et $R$ ). Dans cet article nous développons un procedé théorique basé sur les équations de continuité et sur la théorie de Biot. Le cas particulier d'un solide poreux fibreux est analisé.
\end{abstract}

Abstract -In the application of Biot's theory one of the difficulties is the mechanical characterization of the porous material ( $P, Q$ and $R$ Biot's coefficients). In this paper a theoretical procedure based on the continuity equations and the Biot's theory is developed. The special case of a fibrous porous solid frame is analyzed.

\section{Background theory.}

The Biot's theory predicts both propagation velocity and attenuation of an acoustic wave travelling into a porous material. This theory points out that the two components (solid and fluid) must be considered as a whole, and not as two different parts.

Biot [1] wrote the equation of motion for the two coupled phases, following a Lagrangian procedure and some general stress - strain relations for the porous material. The equations to be solved were

$$
\begin{aligned}
& \nabla^{2}(P e+Q \varepsilon)=\frac{\partial^{2}}{\partial t^{2}}\left(\rho_{11} e+\rho_{12} \varepsilon\right)+b \frac{\partial}{\partial t}(e-\varepsilon)(1 a) \\
& \nabla^{2}(Q e+R \varepsilon)=\frac{\partial^{2}}{\partial t^{2}}\left(\rho_{12} e+\rho_{22} \varepsilon\right)-b \frac{\partial}{\partial t}(e-\varepsilon)(1 b)
\end{aligned}
$$

being $e=e_{x x}+e_{y Y}+e_{2 z}, e_{i j}$ the deformation tensor of the solid part, $\varepsilon$ the deformation tensor of the fluid part, $\rho_{s}$ the density of the solid, $\rho_{E}$ the density of the fluid, $\rho_{12}$ the mass coupling coefficient, $\phi$ the porosity, $\rho_{11}=\rho_{\mathrm{s}}(1-\phi)-\rho_{12}, \quad \rho_{22}=\rho_{\mathrm{f}}(1-\phi)-\rho_{12}, \quad b$ the viscous dissipation coefficient and $P, Q$ and $R$ the Biot's elastic coefficients.

Sometimes the most important problem is to make a general and rigorous derivation of the Biot's elastic coefficients $P, Q$ and $R$. For that reason Biot-Willis [2] calculated expressions which relate $P, Q$ and $R$ with $K_{b}, K_{s}$ and $K_{f}$ (bulk modulus of the solid frame at constant fluid pressure, bulk modulus of the solid frame at constant fluid content, and bulk modulus of the fluid inside the pores, respectively):

$$
P=\frac{(1-\phi)\left(1-\phi-K_{b} / K_{s}\right) K_{s}+\phi\left(K_{s} / K_{f}\right) K_{b}}{1-\phi-K_{b} / K_{s}+\phi K_{s} / K_{f}}+\frac{4}{3} N(2 a)
$$




$$
\begin{aligned}
& Q=\frac{\left(1-\phi-K_{b} / K_{s}\right) \phi K_{s}}{1-\phi-K_{b} / K_{s}+\phi K_{s} / K_{f}}(2 b) \\
& R=\frac{\phi^{2} K_{s}}{1-\phi-K_{b} / K_{s}+\phi K_{s} / K_{f}}(2 c)
\end{aligned}
$$

These elastic coefficients could be obtained experimentally and in some special cases analytically. In fact, in the low porosity case, the selfconsistent theory of composite materials may be employed [3]. On the contrary, in the high porosity case $\left(\phi \rightarrow 1\right.$ and $\left.0<K_{b} / K_{s}<1-\phi\right)$ the simplified expressions are:

$$
P=K_{b}+\frac{4}{3} N+\frac{(1-\phi)^{2}}{\phi} K_{f} ; Q=(1-\phi) K_{f} ; R=\phi K_{f}(3)
$$

To obtain the equation of motion, another way different to the proceaure developed by Biot may be used [4], [5]. This is the case in which, the two phases (solid and fluid) are considered separately. The procedure consist of developing the equation of motion from the continuity, the constitutive and the force balance equations for the solid and the fluid. The obtained equations are:

$$
\begin{array}{r}
-\phi \frac{\partial P_{2}}{\partial x}=\rho_{f} \phi \frac{\partial^{2} \varepsilon}{\partial t^{2}}+b\left(\frac{\partial \varepsilon}{\partial t}-\frac{\partial e}{\partial t}\right)+\phi \rho_{f}(K-1)\left(\frac{\partial^{2} \varepsilon}{\partial t^{2}}-\frac{\partial^{2} e}{\partial t^{2}}\right)(4 a) \\
(1-\phi) \frac{\partial P_{1}}{\partial x}=(1-\phi) \rho_{s} \frac{\partial^{2} e}{\partial t^{2}}+b\left(\frac{\partial \epsilon}{\partial t}-\frac{\partial e}{\partial t}\right)+\phi \rho_{f}(K-1)\left(\frac{\partial^{2} e}{\partial t^{2}}-\frac{\partial^{2} \epsilon}{\partial t^{2}}\right)
\end{array}
$$

here $\mathrm{K}$ is the structure factor and $\mathrm{P}_{1}$ and $\mathrm{P}_{2}$ are given respectively by

$$
\begin{gathered}
P_{1}=\left(\frac{K_{f}(1-\phi) 4 v^{2} / \phi}{1+\beta}+E\right) \frac{\partial e}{\partial x}+\frac{K_{f} 2 v}{1+\beta} \frac{\partial \varepsilon}{\partial x}(5) \\
P_{2}=\frac{K_{f}}{1+\beta}\left(\frac{1-\phi}{\phi} 2 v \frac{\partial e}{\partial x}+\frac{\partial \varepsilon}{\partial x}\right)(6)
\end{gathered}
$$

being

$$
\beta=\frac{\left[(1-\phi) K_{f} 2(1+v)(1-2 v)\right]}{\phi E}
$$

$E$ and $v$ are respectively the Young modulus and the Poisson coefficient of the frame.

\section{Theoretical procedure.}

As it was suggested by Depollier et al. [6] Biot's theory provides the condition of validity of the continuity equations traditionally used for predicting the acoustical properties of porous sound-absorbing 
So, we have

$$
\begin{gathered}
\nabla_{x}^{2}(P e+Q c)=(1-\phi) \frac{\partial P_{1}}{\partial x}(7 a) \\
\nabla_{x}^{2}(Q e+R c)=-\phi \frac{\partial P_{2}}{\partial x}(7 b)
\end{gathered}
$$

and from these equations $P, Q$ and $R$ are deduced as follows:

$$
\begin{gathered}
P=(1-\phi)\left[\frac{K_{f}^{2}(1-\phi) \frac{4 v^{2}}{\phi}}{1+\beta}+E\right](8 a) \\
0=\phi \frac{K_{f}^{2}}{1+\beta} \frac{1-\phi}{\phi} 2 v(8 b) \\
R=\phi \frac{K_{f}^{2}}{1+\beta}(8 c)
\end{gathered}
$$

For the high porosity case it is clear that eq. (3) and eq. (8) give equivalent results. For the general case eq. (2) and eq. (8) have to be compared, being then possible to transfer the requirements for $P, Q$ and $R$ to $K_{b}, K_{s}$ and $k_{f}$. One of the relations that can be obtained is:

$$
K_{b} / K_{s}=-\phi\left(\frac{1-\phi}{\phi} 2 v+1\right)+1
$$

This is an important result, because it gives directly the magnitude of the static coupling coefficient between the solid and the fluid. This coefficient, given by $Q$, is [1]:

$$
Q=\phi\left(1-\frac{K_{b}}{K_{s}}-\phi\right) K_{f}
$$

To calculate $\mathrm{K}_{b} / \mathrm{K}_{\mathrm{s}}$, it is necessary to know the Poisson coefficient of the frame versus porosity. To get it, several models have been employed, and a fibrous structure is considered:a) the contact model [7], b) the rule of mixtures model [8] and, c) the average method [9]. The computed results for the elastic constants of a solid frame made up of nylon fibers $\left(\rho=1046 \mathrm{Kg} / \mathrm{m}^{3}, E=2.895 \times 10^{9} \mathrm{~N} / \mathrm{m}^{2}, v=0.41\right)$ are shown in $\mathrm{fig} .1$. From the average method an anisotropic media is obtained in contradiction with the initial assumptions. So, the theory must be modified to include it. Fig.2 presents the ratio $k_{b} / K_{s}$ versus porosity from the first two models.

\section{Conclusions.}

In this paper we have described a theoretical procedure to obtain the values of the Biot's elastic coefficients, some informations about the jacketed and unjacketed frame bulk modulus and, the magnitude of the 
static coupling coefficient between the solid and the fluid. Three different methods have been used to know the mechanical behaviour of the frame. The results are shown in $\mathrm{Fig.1}$. The $\mathrm{K}_{\mathrm{b}} / \mathrm{K}_{\mathrm{s}}$ ratio is presented in Fig.2. As the porosity increases the obtained predictions from models a) and b) become closer being, on the contrary, the individual fibers interaction (model a) more relevant at lower porosities.

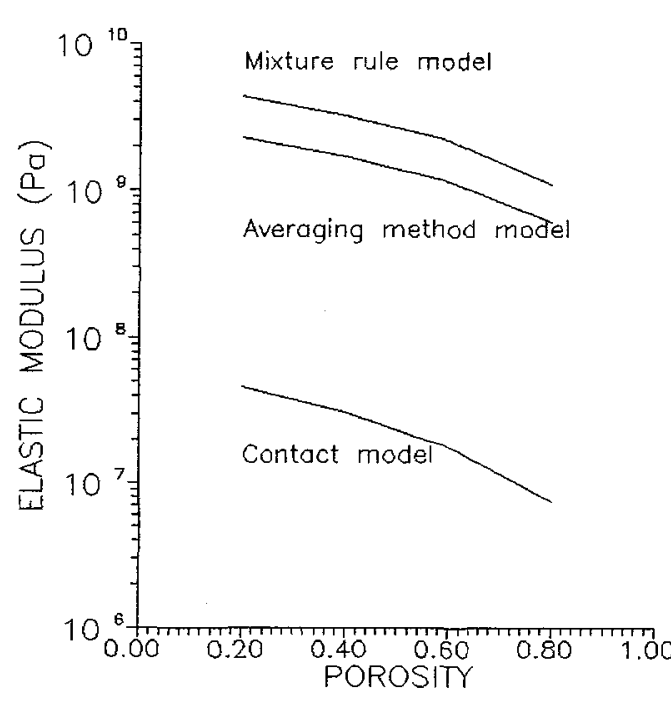

Figure 1. Computed results for a solid frame made up of nylon.

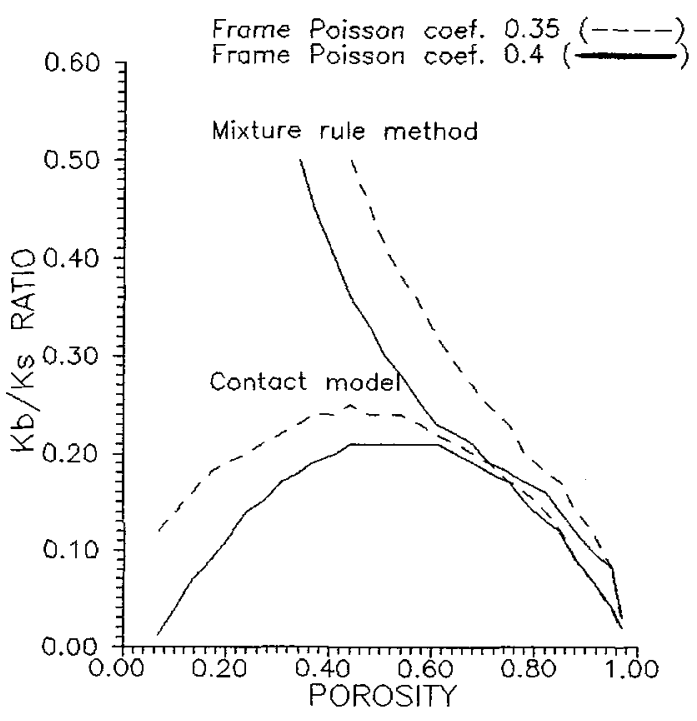

Figure $2, K_{b} / K_{s}$ values versus porosity from models a) and b).

\section{Aknowledgments.}

This work has been supported by the BRITE Project nBE-3009-89.

\section{References.}

1. M.A.Biot, J.Acoust.Soc.Am. 28(2),1956, (168-191).

2. M.A.Biot and D.G.Willis, J.Appl.Mech. 24,1957, (594-601).

3. J.G.Berriman, Appl.Phy.Lett. $37(4), 1980,(382-384)$.

4. C.Zwikker and C.W.Kosten, "Sound Absorbing Materials" (Elsevier N.Y.1949).

5. J.A.Moore and R.H.Lyon, J.Acoust.Soc.Am. $72(6), 1982,(1989-1999)$.

6. C.Depollier, J.F.Allard,W.Lauriks, J.Acoust.Soc.Am. 84(6), 1988, (2277-2279).

7. D.J.Sides, K.Attenborough and K.A.Mulholland, J.Sound and Vib.19(1), 1971, $(49-64)$.

8. J.C.Halpin and S.W.Tsai, AFML-TR-67-423,1967.

9. J.H.Byun and T.W.Chou, J.Text. Inst. 81(4), 1990, (538-548). 